\title{
Awards Presented at the 39th Annual Meeting of the Behavior Genetics Association Saturday, June 20, 2009, Minneapolis, MN
}

The Association's annual awards were presented at the Banquet, held at the Radisson Plaza Hotel. President-Elect Michael Neale served as the master of ceremonies.

The 32nd Annual Thompson Award for the best presentation by an associate member was presented by Eric Turkheimer to Thomas Frisell for his paper "Assortative mating in violent offending: A register study of the total Swedish population 1973-2004".

The fourth annual Fuller and Scott Award for outstanding early career contributions to the field was presented by Local Host Matt McGue to Alex Burt.

The ninth annual Fulker Award for the outstanding paper in Behavior Genetics during the past year was presented by John Hewitt, Editor of Behavior Genetics, to Douglas Mathews and colleagues for their paper "Genetic mapping of vocalization to a series of increasing acute footshocks using B6.A consomic and B6.D2 congenic mouse strains".

Past-President Pierre L. Roubertoux presented the 32nd annual Dobzhansky Award for outstanding lifetime contributions to the field of behavior genetics to David Blizard.

John Loehlin presented the James Shields Award for Excellence in twin research to Eric Turkheimer.

Respectfully Submitted,

Danielle M. Dick

Secretary, Behavior Genetics Association

Pierre L. Roubertoux

Past President, Chair of the BGA Awards Committee 